\title{
Precision Child Health: an Emerging Paradigm for Paediatric Quality and Safety
}

Gregory Costain, $M D, P h D^{1} \odot$

Ronald D. Cohn, $M D^{1,2,3, *}$

David Malkin, $M D^{4,5, *}$

\author{
Address \\ ${ }^{1}$ Division of Clinical and Metabolic Genetics, The Hospital for Sick Children, \\ Department of Pediatrics, University of Toronto, Toronto, Ontario, Canada \\ ${ }^{2}$ Division of Paediatric Medicine, The Hospital for Sick Children, Department of \\ Paediatrics, University of Toronto, Toronto, ON, Canada \\ ${ }^{*}, 3$ Department of Molecular Genetics, University of Toronto, Toronto, 0N, Canada \\ Email: ronald.cohn@sickkids.ca \\ ${ }^{4}$ Division of Hematology/Oncology, The Hospital for Sick Children, Department of \\ Pediatrics, University of Toronto, Toronto, Ontario, Canada \\ ${ }^{*}, 5$ Department of Medical Biophysics, University of Toronto, Toronto, 0N, Canada \\ Email: david.malkin@sickkids.ca
}

Published online: 25 August 2020

(C) Springer Nature Switzerland AG 2020

This article is part of the Topical Collection on Patient Safety

KEYWORDS Precision medicine · Paediatrics - Genetics - Genomics · Genetic testing • Quality of health care

\begin{abstract}
Purpose of Review Precision child health (PCH) is an emerging branch of precision medicine that focuses on the unique needs of the paediatric population. A PCH approach has the potential to enhance both quality of care and patient safety. Genome-wide sequencing can be used as a specific exemplar to showcase current opportunities and forecast future developments.

Recent Findings Information gained from genome-wide sequencing can increase awareness of common and rare medical complications. Care provided to children and their families may then shift from reactive to proactive. Pertinent categories of results from genetic testing include primary diagnostic findings, genetic modifiers of disease expression, and secondary findings. In addition, an individual's unifying genetic diagnosis, disease subtype, and pharmacogenomic profile can all inform drug selection and treatment outcome. Recent lessons learned from the integration of genome-wide sequencing into the clinic may be generalizable to other "big data"-driven interventions.
\end{abstract}


Summary Quality of care and patient safety are key targets of a PCH approach. The genomic revolution offers insights into this proposed new paradigm for healthcare delivery by showcasing the value of accurate diagnosis, disease subtyping with molecular markers, and awareness of individual- or family-specific risk factors for adverse outcomes.

\section{Introduction}

Grouping patients by presenting symptom or clinical diagnosis is a necessary but flawed approach to contemporary care delivery. Quality of care and patient safety issues arise from the marked inter-individual variability in clinical presentations, disease courses, and responses to standard-of-care interventions. New technologies are enabling increased precision in classifying diseases and identifying at-risk states for adverse outcomes. The development of standardized procedures and protocols has been a key component of many successful quality and safety initiatives. The next frontier of medicine is to better understand the origins of atypical idiosyncratic outcomes in relation to these protocols.

Precision medicine refers to the goal of leveraging extensive patient-level phenotypic and genotypic data to tailor care recommendations, and thereby improve health outcomes. Precision child health (PCH), a term coined by one of us (R.D.C.), focuses on the unique needs of the paediatric population. These include the differing physiologic and social determinants of health, disease landscape, and genetic architecture: interrogating data from the genetic code to the postal code. PCH necessitates the integration of large datasets, including but not limited to genomic data. Artificial intelligence and machine learning approaches suggest that operationalizing $\mathrm{PCH}$ is increasingly tractable. The aim is a more predictive and preventative approach to medicine that builds on established standardized care protocols by identifying the individuals for whom we should divert from these protocols.

In this commentary, we will discuss how a $\mathrm{PCH}$ approach can enhance quality and safety. At our quaternary care centre, complex paediatric morbidity and mortality are often associated with a known or suspected genetic condition. Many contemporary clinical examples illustrating the power and the promise of $\mathrm{PCH}$ are the result of translational genomics. Our institution has identified genomic medicine as a priority area and is participating in multiple large-scale sequencing initiatives, ranging from constitutional ("germline") DNA to tumours to microbiomes. We will therefore focus on genome-wide sequencing as a specific exemplar, to showcase current opportunities and forecast future developments.

\section{Improving quality of care through molecular diagnostics and disease subtyping}

Diagnostic error is an important issue in paediatric medicine [1]. Information gained from genome-wide sequencing can increase awareness of potential common and rare medical complications. Care provided to children and their families may then shift from reactive to proactive. Pertinent categories of results from genetic testing include primary diagnostic findings, genetic modifiers of disease expression, and secondary findings.

Individually rare genetic conditions are a collectively important cause of severe paediatric morbidity and mortality $[2,3]$. In children with suspected genetic disorders who remain undiagnosed after an initial assessment, whole exome sequencing (WES) and whole genome sequencing (WGS) can increase 
the absolute yield of primary diagnostic findings to 30-50\% [4-9]. WES is more widely available clinically and involves sequencing the $~ 1 \%$ of DNA that represents exons of protein-coding genes. WGS offers several advantages compared with WES and is a comprehensive genetic test potentially capable of detecting nearly all sequence and structural variation in the human genome $[9,10 \bullet, 11]$. WES and WGS were first used as "last resort" tests after a prolonged diagnostic odyssey. Many groups are now advocating for their use as first- or second-tier tests for presentations associated with significant genetic heterogeneity $[9,12,13 \bullet]$. Non-specific features such as global developmental delay, hypotonia, seizures, or congenital anomalies can increasingly be classified by a precise molecular genetic diagnosis. The potential benefits for families and care providers are significant. A genetic diagnosis can inform prognosis, anticipatory care and surveillance, targeted management, and family planning. Standardized procedures and protocols may need to be modified for these children. From a patient quality of care and safety perspective, timely diagnosis may eliminate the need for other invasive testing or costly healthcare expenditures [6]. In some instances, the specific genetic variants identified may have prognostic or other implications beyond those of the overarching genetic diagnosis.

Most genetic conditions are characterized by variable expressivity even within families. This represents a major obstacle to individualizing risk predictions. An archetypal example is 22q11.2 deletion syndrome (formerly DiGeorge syndrome). For this common chromosomal disorder, the risk for major features like cardiac outflow tract anomalies or schizophrenia is incomplete, and the degree of cognitive impairment can be highly variable [14]. Beyond primary diagnostic findings, genomewide sequencing (especially WGS) captures information about the genetic background. This includes common and rare DNA variation that may act individually or in an aggregate model to modify disease expression [15-17]. Studying genome-wide data from patients has revealed an unexpected level of complexity for even genetically "simple" disorders like cystic fibrosis [18]. Nonetheless, we anticipate increased opportunities to individualize risk profiles after diagnosis by interrogating the remainder of the genome-wide sequencing data. Non-genetic factors including social determinants of health shape both disease expression and the lived experienced of the genetic condition; integrating this "postal code" information with the genetic code information is the eventual goal of the $\mathrm{PCH}$ paradigm.

Secondary findings are another potential benefit derived from genome-wide sequencing. In contrast to primary genetic findings, these are unrelated to the initial indication for testing but may have profound health implications for the individual and the family. A common current clinical standard is to offer reporting of known or expected pathogenic (disease-causing) variants in 59 genes that are associated with highly penetrant "medically actionable" conditions [19]. Examples include cancer predisposition syndromes (e.g., LiFraumeni syndrome and multiple endocrine neoplasia) and conditions predisposing to severe adverse cardiac events (e.g., Brugada syndrome, long QT syndrome, and Loeys-Dietz syndrome). This gene list was produced by the American College of Medical Genetics and Genomics (ACMG) and was last 
revised in 2017 [19]. Additional genes are likely to be added in the future [20]. The laboratory threshold for reporting secondary findings is higher than for putative primary findings, in an attempt to limit false positives which, if acted upon, could lead to unnecessary or unsafe invasive diagnostic procedures or therapeutic interventions. Remarkably, $1-3 \%$ of patients are identified as having a reportable secondary finding after undergoing WES, and the genetic variant is inherited in most cases [21, 22]. Family history was either negative or non-specific in many instances. Long-term follow-up of these families is expected to show improvements in health outcomes as a result of presymptomatic or early detection.

\section{Leveraging genomic data in the service of safe and efficacious drug treatment}

Safe prescribing in paediatric medicine is a complex issue. An individual's unifying genetic diagnosis, disease subtype, and pharmacogenomic profile can all inform drug selection and treatment outcome. Within a PCH framework, genome-wide sequencing data can uniquely inform treatment with novel and established therapies.

The complex genetic architecture of common paediatric presentations has implications for treatment. In paediatric oncology, both germline variation (in all cells of the body) and somatic genetic variation (in the tumour only) can inform treatment protocol and trial eligibility. Similarly, in other areas of paediatrics an accurate molecular diagnosis is increasingly a prerequisite for accessing targeted therapeutics or participating in clinical trials. For example, specialized treatments now available for spinal muscular atrophy (SMA) are specifically targeting the deficiency in SMN1 protein [23, 24]. Distinguishing a specific condition like SMA from its "phenocopies" and "genocopies" is essential when the treatment targets a particular mechanism or pathway. Precision therapeutics are emerging for relatively common rare diseases like Duchenne muscular dystrophy, cystic fibrosis, and sickle cell disease. In the extreme, proof-of-principle exists for " $n=1$ therapy" designed for a specific individual based on their own unique genetic variant [25•]. Evaluating and affording genetic-informed therapies for rare diseases may necessitate deviating from standard processes $[26,27]$. More work is needed to understand the key features beyond the genetic code that shape an individual's safety profile and response to treatment.

Genetic germline findings are highly stable, in contrast to those from other laboratory or imaging investigations that reflect a dynamic physiologic state. Having genome-wide sequencing data already available for real-time queries could therefore enhance patient safety. For example, research at our centre has demonstrated that pre-existing WGS data can be interrogated for clinically actionable pharmacogenetic variants [28]. This will remove one barrier to incorporating pharmacogenetic information into real-time decision-making, which is turn-around time. Avoidance of adverse drug reactions and safe prescribing can be enhanced by alerting the ordering provider immediately to pertinent pharmacogenetic variation previously identified in the patient. Integrating pharmacogenetics into clinical practice has been challenging, but there are now enough successes to justify continued support for this aspect of care delivery [29]. 


\section{Identifying lessons learned from clinical genome-wide} sequencing

The global coronavirus disease (COVID-19) pandemic has illustrated both the need for precision approaches [30], as well as the potential risks associated with expediting or adapting established regulatory processes [31]. In fact, the current pandemic reflects a perfect example of how a public health crisis can only be managed efficiently by understanding the individual response to infectivity, transmission, and overall disease burden. Standard regulatory processes have been developed over many years, if not decades, and they continue to evolve as new technologies and health care applications emerge. In the case of genome-wide sequencing, gradual adoption into clinical practice was shaped by legitimate questions about its analytic validity, clinical validity, and clinical utility. A first step was ensuring that there were sufficient research data to justify trialling its use in patient-care settings. For WES, this occurred over a timespan of approximately 57 years. The use of an objective set of assessment criteria (such as the ACCE (Analytic validity, Clinical validity, Clinical utility, and associated Ethical, legal and social implications) model for genetic tests [32]) can help to counterbalance the commercial and research interests that may initially be driving innovation. Genome-wide sequencing is not a diagnostic panacea, and transparency about its limitations remains a key component of pre-test counselling. Moreover, research studies do not always address the question of how to scale without sacrificing quality and safety. Ongoing surveillance is needed after a test first becomes available in clinical practice to ensure that standards are maintained and that implementation issues are addressed; ongoing pharmacovigilance is similarly a requirement for orphan drugs [33]. While WES and WGS can facilitate timely and accurate diagnosis, these tests also do not address system-related issues derived from ongoing patient care needs [34]. For example, while there may be the possibility of providing a specialized treatment for a newly diagnosed genetic condition, accessing this for the patient in a timely manner is often challenging [34, 35].

Genomic data-like other personal health information-warrant rigorous safeguards to protect privacy and prevent misuse. A more unique consideration relates to individual-level benefits of genomic data being tied to populationscale data-sharing efforts that facilitate variant interpretation and genotypephenotype correlations. $\mathrm{PCH}$ will necessitate learning from and leveraging massive clinical sequencing datasets. For these reasons, planning is underway at our centre to ensure responsible inter- and intra-institutional data sharing and to facilitate ongoing quality improvement and research. Data storage and the integration of sequencing data with electronic medical records are similarly complex but necessary components of a PCH strategy [36, 37•]. The major legal, ethical, and information technology aspects of these undertakings necessitate adequate representation on planning committees.

\section{Summary and future directions}

Quality of care and patient safety are key targets of a PCH approach (Table 1). Individualizing care recommendations based on the totality of information 
Table 1. Opportunities provided by a precision child health ( $\mathrm{PCH})$ paradigm to prevent harm and mitigate risk in paediatric medicine

\begin{tabular}{|c|c|c|}
\hline Safety issue & General approach within PCH & 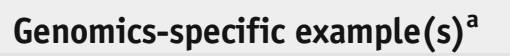 \\
\hline Diagnostic error & $\begin{array}{l}\text { Use of new technologies to improve the nature and } \\
\text { resolution of the available data (from genotype to } \\
\text { phenotype) and of machine learning and artificial } \\
\text { intelligence approaches to better interpret these } \\
\text { data }\end{array}$ & $\begin{array}{l}\text { - Improved diagnostic yield in } \\
\text { heterogeneous disease populations, } \\
\text { with genome-wide sequencing }\end{array}$ \\
\hline $\begin{array}{l}\text { Missed opportunity for } \\
\text { pre-symptomatic or ear- } \\
\text { ly detection of disease }\end{array}$ & $\begin{array}{l}\text { Gathering extensive real-time physiologic data and } \\
\text { cataloguing background risk factors to facilitate } \\
\text { personalized risk stratification }\end{array}$ & $\begin{array}{l}\text { - Use of genome-wide data to individ- } \\
\text { ualize risk predictions } \\
\text { - Identification of secondary and } \\
\text { incidental findings by genome-wide } \\
\text { testing }\end{array}$ \\
\hline Treatment failure & $\begin{array}{l}\text { Drug selection that is informed by the specific } \\
\text { aetiopathogenesis of an individual's symptom or } \\
\text { disease }\end{array}$ & $\begin{array}{l}\text { - Molecular disease subtyping to guide } \\
\text { selection of a specific standard } \\
\text { treatment } \\
\text { - Genetic-informed therapies (disease } \\
\text { specific and variant specific) }\end{array}$ \\
\hline Adverse drug event & $\begin{array}{l}\text { Incorporating knowledge of pharmacokinetic and } \\
\text { pharmacodynamic factors operating at an } \\
\text { individual level (both static and transient) }\end{array}$ & - Pharmacogenetic profiling \\
\hline
\end{tabular}

available about that patient is an ambitious but increasingly realistic prospect. PCH will build on, rather than replace, established standard operating procedures. The genomic revolution offers insights into this proposed new paradigm for healthcare delivery by showcasing the value of accurate diagnosis, disease subtyping with molecular markers, and awareness of individual- or familyspecific risk factors for adverse outcomes (Table 1). Lessons learned from the integration of genome-wide sequencing into the clinic may be generalizable to other "big data"-driven interventions, including those supported by machine learning and artificial intelligence.

\section{Acknowledgements}

The authors thank their colleagues at The Hospital for Sick Children for thoughtful discussions related to precision child health.

\section{Compliance with Ethical Standards}

\section{Conflict of Interest}

Gregory Costain declares that he has no conflict of interest. Ronald D. Cohn declares that he has no conflict of interest. David Malkin declares that he has no conflict of interest. 


\section{References and Recommended Reading}

Papers of particular interest, published recently, have been highlighted as:

- Of importance

1. Matlow AG, Baker GR, Flintoft V, Cochrane D, Coffey $\mathrm{M}$, Cohen $\mathrm{E}$, et al. Adverse events among children in Canadian hospitals: the Canadian Paediatric Adverse Events Study. CMAJ. 2012;184(13):E709-18. https:// doi.org/10.1503/cmaj.112153.

2. Wright CF, FitzPatrick DR, Firth HV. Paediatric genomics: diagnosing rare disease in children. Nat Rev Genet. 2018;19(5):253-68. https://doi.org/10.1038/ nrg.2017.116.

3. Gonzaludo N, Belmont JW, Gainullin VG, Taft RJ. Estimating the burden and economic impact of pediatric genetic disease. Genet Med. 2019;21(8):1781-9. https://doi.org/10.1038/s41436-018-0398-5.

4. Stavropoulos DJ, Merico D, Jobling R, Bowdin S, Monfared N, Thiruvahindrapuram B, et al. Whole genome sequencing expands diagnostic utility and improves clinical management in pediatric medicine. NPJ Genom Med. 2016;1. https://doi.org/10.1038/ npigenmed.2015.12.

5. Meng L, Pammi M, Saronwala A, Magoulas P, Ghazi $\mathrm{AR}$, Vetrini F, et al. Use of exome sequencing for infants in intensive care units: ascertainment of severe singlegene disorders and effect on medical management. JAMA Pediatr. 2017;171(12):e173438. https://doi.org/ 10.1001/jamapediatrics.2017.3438.

6. Tan TY, Dillon OJ, Stark Z, Schofield D, Alam K, Shrestha R, et al. Diagnostic impact and costeffectiveness of whole-exome sequencing for ambulant children with suspected monogenic conditions. JAMA Pediatr. 2017;171(9):855-62. https://doi.org/10. 1001/jamapediatrics.2017.1755.

7. Posey JE, Harel T, Liu P, Rosenfeld JA, James RA, Coban Akdemir ZH, et al. Resolution of disease phenotypes resulting from multilocus genomic variation. $\mathrm{N}$ Engl J Med. 2017;376(1):21-31. https://doi.org/10.1056/ NEJMoa1516767.

8. Clark MM, Stark Z, Farnaes L, Tan TY, White SM, Dimmock D, et al. Meta-analysis of the diagnostic and clinical utility of genome and exome sequencing and chromosomal microarray in children with suspected genetic diseases. NPJ Genom Med. 2018;3:16. https:// doi.org/10.1038/s41525-018-0053-8.

9. Lionel AC, Costain G, Monfared N, Walker S, Reuter MS, Hosseini SM, et al. Improved diagnostic yield compared with targeted gene sequencing panels suggests a role for whole-genome sequencing as a first-tier genetic test. Genet Med. 2018;20(4):435-43. https:// doi.org/10.1038/gim.2017.119.

10. Turro E, Astle WJ, Megy K, Graf S, Greene D, Shamardina $\mathrm{O}$, et al. Whole-genome sequencing of patients with rare diseases in a national health system Nature. 2020. https://doi.org/10.1038/s41586-0202434-2 A landmark study demonstrating that the diagnosis of rare genetic conditions can be enhanced by integrating clinical testing with whole-genome sequencing and research on a national scale.

11. Bick D, Jones M, Taylor SL, Taft RJ, Belmont J. Case for genome sequencing in infants and children with rare, undiagnosed or genetic diseases. J Med Genet. 2019;56:783-91. https://doi.org/10.1136/jmedgenet2019-106111.

12. Srivastava S, Love-Nichols JA, Dies KA, Ledbetter DH, Martin CL, Chung WK, et al. Meta-analysis and multidisciplinary consensus statement: exome sequencing is a first-tier clinical diagnostic test for individuals with neurodevelopmental disorders. Genet Med. 2019;21(11):2413-21. https://doi.org/10.1038/ s41436-019-0554-6.

13. Reuter MS, Chaturvedi RR, Liston E, Manshaei R, Aul $\mathrm{RB}$, Bowdin S, et al. The Cardiac Genome Clinic: implementing genome sequencing in pediatric heart disease. Genet Med. 2020. https://doi.org/10.1038/ s41436-020-0757-x A proof-of-concept study illustrating how genome sequencing data can be integrated into multiple facets of clinical care in a paediatric disease population.

14. McDonald-McGinn DM, Sullivan KE, Marino B, Philip N, Swillen A, Vorstman JA, et al. 22q112 deletion syndrome. Nat Rev Dis Primers. 2015;1:15071. https:// doi.org/10.1038/nrdp.2015.71.

15. Bassett AS, Lowther C, Merico D, Costain G, Chow EWC, van Amelsvoort T, et al. Rare genome-wide copy number variation and expression of schizophrenia in 22q11.2 deletion syndrome. Am J Psychiatry. 2017;174(11):1054-63. https://doi.org/10.1176/appi. ajp.2017.16121417.

16. Zhao Y, Diacou A, Johnston HR, Musfee FI, McDonaldMcGinn DM, McGinn D, et al. Complete sequence of the 22q11.2 allele in 1,053 subjects with 22q11.2 deletion syndrome reveals modifiers of conotruncal heart defects. Am J Hum Genet. 2020;106(1):26-40. https:// doi.org/10.1016/j.ajhg.2019.11.010.

17. Cleynen I, Engchuan W, Hestand MS, Heung T, Holleman AM, Johnston HR, et al. Genetic contributors to risk of schizophrenia in the presence of a 22q11.2 deletion. Mol Psychiatry. 2020. https://doi. org/10.1038/s41380-020-0654-3.

18. Gong J, Wang F, Xiao B, Panjwani N, Lin F, Keenan K, et al. Genetic association and transcriptome integration identify contributing genes and tissues at cystic fibrosis modifier loci. PLoS Genet. 2019;15(2):e1008007. https://doi.org/10.1371/journal.pgen.1008007.

19. Kalia SS, Adelman K, Bale SJ, Chung WK, Eng C, Evans $\mathrm{JP}$, et al. Recommendations for reporting of secondary findings in clinical exome and genome sequencing, 2016 update (ACMG SF v2.0): a policy statement of 
the American College of Medical Genetics and Genomics. Genet Med. 2017;19(2):249-55. https://doi.org/ 10.1038/gim.2016.190.

20. Webber EM, Hunter JE, Biesecker LG, Buchanan AH, Clarke EV, Currey E, et al. Evidence-based assessments of clinical actionability in the context of secondary findings: updates from ClinGen's Actionability Working Group. Hum Mutat. 2018;39(11):1677-85. https://doi.org/10.1002/humu.23631.

21. Hart MR, Biesecker BB, Blout CL, Christensen KD, Amendola LM, Bergstrom KL, et al. Secondary findings from clinical genomic sequencing: prevalence, patient perspectives, family history assessment, and healthcare costs from a multisite study. Genet Med. 2019;21(5):1100-10. https://doi.org/10.1038/ s41436-018-0308-x.

22. Haer-Wigman $\mathrm{L}$, van der Schoot V, Feenstra I, Vultovan Silfhout AT, Gilissen C, Brunner HG, et al. 1 in 38 individuals at risk of a dominant medically actionable disease. Eur J Hum Genet. 2019;27(2):325-30. https:// doi.org/10.1038/s41431-018-0284-2.

23. Finkel RS, Mercuri E, Darras BT, Connolly AM, Kuntz NL, Kirschner J, et al. Nusinersen versus sham control in infantile-onset spinal muscular atrophy. N Engl J Med. 2017;377(18):1723-32. https://doi.org/10. 1056/NEJMoa1702752.

24. Mendell JR, Al-Zaidy S, Shell R, Arnold WD, RodinoKlapac LR, Prior TW, et al. Single-dose gene-replacement therapy for spinal muscular atrophy. N Engl J Med. 2017;377(18):1713-22. https://doi.org/10. 1056/NEJMoa1706198.

25. Kim J, Hu C, Moufawad El Achkar C, Black LE, Douville J, Larson A, et al. Patient-Customized Oligonucleotide Therapy for a Rare Genetic Disease. N Engl J Med. 2019;381(17):1644-52. https://doi.org/10. 1056/NEJMoa1813279An illustration of rapid creation, testing, and administration of an individualized therapy for a rare genetic condition, which challenges some of the traditional aspects of drug development and regulatory approval.

26. Day S, Jonker AH, Lau LPL, Hilgers RD, Irony I, Larsson $\mathrm{K}$, et al. Recommendations for the design of small population clinical trials. Orphanet J Rare Dis. 2018;13(1):195. https://doi.org/10.1186/s13023-0180931-2.

27. Ballreich J, Ezebilo I, Sharfstein J. Affording genetic therapies in the Medicaid program. JAMA Pediatr. 2020;174:523. https://doi.org/10.1001/ jamapediatrics.2020.0168.

28. Cohn I, Paton TA, Marshall CR, Basran R, Stavropoulos DJ, Ray PN, et al. Genome sequencing as a platform for pharmacogenetic genotyping: a pediatric cohort study. NPJ Genom Med. 2017;2:19. https://doi.org/10.1038/ s41525-017-0021-8.

29. Roden DM, McLeod HL, Relling MV, Williams MS, Mensah GA, Peterson JF, et al. Pharmacogenomics.
Pharmacogenomics Lancet. 2019;394(10197):52132. https://doi.org/10.1016/S0140-6736(19)31276-0.

30. Shrestha GS, Paneru HR, Vincent JL. Precision medicine for COVID-19: a call for better clinical trials. Crit Care. 2020;24(1):282. https://doi.org/10.1186/ s13054-020-03002-5.

31. Canada H. Spartan cube Covid-19 system (2020-0505) Medical Device Recall. 2020. https:// healthycanadians.gc.ca/recall-alert-rappel-avis/hc-sc/ 2020/72971r-eng.php\#reason-motif. Accessed 14 June 2020.

32. Haddow JE, Palomaki GE. ACCE: A model process for evaluating data on emerging genetic tests. In: Khoury $\mathrm{M}$, Little J, Burke W, editors. Human genome epidemiology: a scientific foundation for using genetic information to improve health and prevent disease: Oxford University Press; 2003. p. 217-33.

33. Sardella M, Belcher G. Pharmacovigilance of medicines for rare and ultrarare diseases. Ther Adv Drug Saf. 2018;9(11):631-8. https://doi.org/10.1177/ 2042098618792502.

34. Kingsmore SF, Ramchandar N, James K, Niemi AK, Feigenbaum A, Ding Y, et al. Mortality in a neonate with molybdenum cofactor deficiency illustrates the need for a comprehensive rapid precision medicine system. Cold Spring Harbor Mol Case Stud. 2020;6(1). https://doi.org/10.1101/mcs.a004705.

35. Costain G, Moore AM, Munroe L, Williams A, Zlotnik Shaul R, Rockman-Greenberg C, et al. Enzyme replacement therapy in perinatal hypophosphatasia: case report of a negative outcome and lessons for clinical practice. Mol Genet Metab Rep. 2018;14:22-6. https:// doi.org/10.1016/j.ymgmr.2017.10.006.

36. Gottesman O, Kuivaniemi H, Tromp G, Faucett WA, Li R, Manolio TA, et al. The Electronic Medical Records and Genomics (eMERGE) Network: past, present, and future. Genet Med. 2013;15(10):761-71. https://doi. org/10.1038/gim.2013.72.

37. Bycroft C, Freeman C, Petkova D, Band G, Elliott LT, Sharp K, et al. The UK Biobank resource with deep phenotyping and genomic data. Nature. 2018;562(7726):203-9. https://doi.org/10.1038/ s41586-018-0579-zA description of the UK Biobank open resource, which highlights both challenges associated with managing "big data" as well as unique opportunities for advancing precision medicine.

\section{Publisher's Note}

Springer Nature remains neutral with regard to jurisdictional claims in published maps and institutional affiliations. 